\title{
Decreased levels of uric acid after oral glucose challenge is associated with triacylglycerol levels and degree of insulin resistance
}

\author{
F. J. Tinahones ${ }^{1}$, F. Cardona ${ }^{1}$, G. Rojo-Martínez ${ }^{2}$, M. C. Almaraz ${ }^{3}$, I. Cardona ${ }^{2}$, J. Vázquez-Mellado ${ }^{4}$, \\ L. Garrido-Sánchez ${ }^{2}$, E. Collantes ${ }^{5}$ and F. Soriguer ${ }^{3}$ \\ ${ }^{1}$ Servicio de Endocrinología y Nutrición, Hospital Clínico Universitario Virgen de la Victoria, Málaga and CIBER Fisiopatología \\ de la obesidad y nutrición CB06/03 Instituto de Salud Carlos III, Málaga, Spain \\ ${ }^{2}$ Fundación IMABIS (Instituto Mediterráneo para el Avance de la Biotecnología y la Investigación Sanitaria), Málaga, Spain \\ ${ }^{3}$ Servicio de Endocrinología y Nutrición, Hospital Regional Universitario Carlos Haya, Málaga, Spain \\ ${ }^{4}$ Hospital General Ciudad de México, México DF \\ ${ }^{5}$ Servicio de Reumatología, Hospital Universitario Reina Sofía de Córdoba, Spain
}

(Received 29 March 2007 - Revised 29 May 2007 - Accepted 31 May 2007)

Hyperuricaemia is one of the components of metabolic syndrome. Both oxidative stress and hyperinsulinism are important variables in the genesis of this syndrome and have a close association with uric acid (UA). We evaluated the effect of an oral glucose challenge on UA concentrations. The study included 656 persons aged 18 to 65 years. Glycaemia, insulin, UA and plasma proteins were measured at baseline and 120 min after an oral glucose tolerance test (OGTT). The baseline sample also included measurements of total cholesterol, triacylglycerol (TAG) and HDL-cholesterol. Insulin resistance was calculated with the homeostasis model assessment. UA levels were significantly lower after the OGTT (281.93 (SD 92.19) v. 267.48 (SD 90.40) $\mu \mathrm{mol} / 1 ; P<0.0001$ ). Subjects with a drop in UA concentrations $>40.86 \mu \mathrm{mol} / 1$ ( $>75$ th percentile) had higher plasma TAG levels $(P=0.0001)$, baseline insulin $(P=0.02)$ and greater insulin resistance $(P=0.034)$. Women with a difference in plasma concentrations of UA above the 75th percentile had higher baseline insulin levels $(P=0.019)$, concentration of plasma TAG $(P=0.0001)$ and a greater insulin resistance index $(P=0.029)$, whereas the only significant difference in men was the level of TAG. Multiple regression analysis showed that the basal TAG levels, insulin at $120 \mathrm{~min}$, glycaemia at $120 \mathrm{~min}$ and waist:hip ratio significantly predicted the variance in the UA difference $\left(r^{2}\right.$ 0.077). Levels of UA were significantly lower after the OGTT and the individuals with the greatest decrease in UA levels are those who have greater insulin resistance and higher TAG levels.

Uric acid: Insulin resistance: OGTT: Triacylglycerol

The metabolic syndrome is tightly associated with hyperuricaemia $^{1-3}$. TAG levels are directly associated with uric acid levels and these associations seem to be also related to several genetic polymorphisms ${ }^{4-7}$. We have also reported that hyperuricaemic-hypertriacylglycerolaemic patients have high levels of VLDL components and a reduced fractionated excretion of uric acid $^{7}$.

The association between serum uric acid and the metabolic syndrome seems to be related to insulin resistance. Insulin acts in the proximal tubules and interferes with excretion of $\mathrm{Na}$ and uric acid under physiological states. Hyperinsulinaemia has been associated with decreased urate and $\mathrm{Na}$ excretion and thus with hypertension and hyperuricaemia. It seems that higher insulin resistance is also associated with higher serum uric acid levels, although most studies reporting this association were done in healthy subjects and under fasting or baseline conditions ${ }^{8,9}$.

Oxidative stress has recently been shown to play an important role in the genesis of the metabolic syndrome ${ }^{10}$. The metabolization of purins has a paradoxical effect on oxidative stress. On the one hand, the action of xanthine oxidase on xanthine produces uric acid and superoxide radicals that are derived from reactive oxygen species ${ }^{11}$, and on the other hand is the antioxidant effect of uric acid itself. This paradox has resulted in some studies showing that the administration of allopurinol, which is hypouricaemic, reduces reactive oxygen species ${ }^{12}$, whilst others show that the rise in uric acid concentrations increases the antioxidant capacity of plasma $^{13,14}$.

An oral glucose tolerance test (OGTT) causes an increase in insulin levels and oxidative stress, both in persons with diabetes and in healthy persons ${ }^{15,16}$. Recent studies have shown that hyperglycaemia induces an overproduction of superoxide by the mitochondrial electron-transport chain ${ }^{17}$. Superoxide overproduction is accompanied by increased NO generation, due to endothelial NO synthase and inducible NO synthase uncoupled state, a phenomenon favouring the formation of the strong oxidant peroxynitrite. Additionally, during an oral glucose challenge, a reduction in the antioxidant defences is observed $^{18-21}$. 
Considering that uric acid may play a role in oxidative stress and that it has a direct relation with insulin levels, and aware that an oral glucose challenge increases oxidative stress and insulin levels, we sought to determine whether an OGTT was able to modify plasma levels of uric acid. Furthermore, we attempted to determine the possible association between this hypothetical change in uric acid levels and the levels of TAG, which is the variable in the metabolic syndrome that is most closely related with hyperuricaemia.

\section{Subjects and methods}

A total of 656 persons aged 18-65 years, selected randomly from the municipal census, were included in the present study. The general characteristics of the study have been reported elsewhere ${ }^{22}$. Pregnant women, hospitalized patients or those who lived in health institutions, as well as those with severe psychological disorders, were excluded. The subjects were requested by mail to attend their local health centre for a medical examination. Those who failed to attend their first appointment were sent a second letter giving them another appointment and all those still not attending were visited at home in order to ascertain the reason. The final sample distribution by age and sex was not significantly different from the population distribution ${ }^{23}$.

\section{Procedures}

All subjects were interviewed and given a standardized clinical examination based on standard procedures performed by the same researchers. The clinical data included weight, height, BMI (weight $(\mathrm{kg}) /$ height $\left.(\mathrm{m})^{2}\right)$, hip circumference, abdominal circumference and waist:hip ratio, all measured as usual. An OGTT was given to all the participants. Blood samples were taken from all the subjects at baseline and $120 \mathrm{~min}$ after the OGTT. The plasma was separated and frozen at $-70^{\circ} \mathrm{C}$ for later analysis.

Glycaemia, uric acid and plasma proteins were measured at baseline and $120 \mathrm{~min}$ after the OGTT (Dimension autoanalyzer; Dade Behring Inc., Deerfield, IL, USA). Measurements were also made in the baseline sample of total cholesterol, TAG and HDL-cholesterol by enzymatic methods in an autoanalyzer (Dimension; Dade Behring Inc.). Baseline insulin levels were measured by RIA administered by BioSource S.A. (Biosource Europe SA, Nivelles, Belgium) and insulin resistance was calculated from the homeostasis model assessment (HOMA) with the formula: insulin resistance $=$ [fasting serum insulin $(\mu \mathrm{U} / \mathrm{ml}) \times$ fasting blood glucose $(\mathrm{mmol} / \mathrm{l})] / 22 \cdot 5^{24}$ and HOMA-IS $=($ fasting insulin $(\mu \mathrm{U} / \mathrm{ml}) \times 20) /($ fasting glucose $(\mathrm{mmol} / \mathrm{l})-3.5)$.

\section{Statistical analysis}

The data are presented as means and standard deviations. The 75 th percentile $(\delta \mathrm{P} 75)$ of the frequency distribution of the difference between uric acid at baseline and after the OGTT was used as the cut-off point for changes in the levels of uric acid during the OGTT. The percentiles for the uric acid difference were: $25-18.230 ; 50$ 8.862; $7540.874 \mu \mathrm{mol} / \mathrm{l}$.

Means contrast was done with the Student $t$ test and bivariate correlations by calculating the linear correlation coefficient (Pearson r). The contribution of different variables to the variance in uric acid level change between baseline and $120 \mathrm{~min}$ was calculated by multiple regression models. In all cases the rejection level for a null hypothesis was set at $\alpha=0 \cdot 05$. The statistical analysis was done with SPSS 12.0 for Windows (SPSS Inc., Chicago, IL, USA). The study was approved by the Ethics and Clinical Investigation Committee of Carlos Haya Hospital.

\section{Results}

Table 1 shows the age, sex and the baseline and 120-min values for uric acid, total proteins, glucose and insulin, as well as the TAG level, BMI, waist:hip ratio, Homeostasis model assessment-insulin resistance (HOMA-IR), HOMAinsulin secretion (IS), HDL-cholesterol and LDL-cholesterol in the study population. The levels of uric acid were significantly lower after the OGTT (281.93 (SD 92.19) v. 267.48 (SD 90.40) $\mu \mathrm{mol} / 1 ; P<0.0001$ ).

The subjects with the greatest differences between uric acid values at baseline and after $120 \mathrm{~min}(\delta \mathrm{P} 75)$ also had the highest levels of TAG $(P<0.001)$, baseline insulinaemia $(P<0.02)$, HOMA-IS $(P<0.023)$ and HOMA-IR $(P<0.034)$. Women with a difference in plasma uric acid levels above the 75 th percentile had higher baseline insulin levels $(P=0 \cdot 019)$, higher concentrations of plasma TAG $(P=0.0001)$ and a greater insulin resistance index $(P=0 \cdot 029)$, whereas the men only had a significant difference in TAG levels (Table 2).

The baseline uric acid level correlated negatively with HDLcholesterol and positively with cholesterol, TAG, age, BMI, baseline and 120-min insulinaemia and glycaemia, HOMA-IR and HOMA-IS. The difference in the uric acid levels between baseline and $120 \mathrm{~min}$ after the OGTT was significantly associated with plasma TAG, cholesterol and glycaemia at $120 \mathrm{~min}$ ( $r$ 0.23, $P<0.001, r 0.10, P=0.006, r 0.092$ and $P=0.022$, respectively) (Table 3 ). Separate correlation analyses according to sex showed no differences (data not shown).

Table 1. Biological characteristics of the study population* (Mean values and standard deviations)

\begin{tabular}{|c|c|c|}
\hline & Mean & SD \\
\hline Age (years) & $46 \cdot 10$ & $13 \cdot 41$ \\
\hline \multicolumn{3}{|l|}{ Sex } \\
\hline Men & \multicolumn{2}{|c|}{227} \\
\hline Women & \multicolumn{2}{|c|}{429} \\
\hline BMI $\left(\mathrm{kg} / \mathrm{m}^{2}\right)$ & $28 \cdot 31$ & $5 \cdot 22$ \\
\hline Waist:hip ratio & 0.89 & 0.11 \\
\hline Cholesterol $(\mathrm{mmol} / \mathrm{l})$ & 6.53 & 1.40 \\
\hline TAG (mmol/l) & $1 \cdot 25$ & 0.87 \\
\hline HDL-cholesterol (mmol/l) & $1 \cdot 75$ & 0.42 \\
\hline Glycaemia baseline (mmol/l) & $5 \cdot 67^{\mathrm{a}}$ & 1.01 \\
\hline Glycaemia $120 \mathrm{~min}(\mathrm{mmol} / \mathrm{l})$ & $6 \cdot 00^{\mathrm{a}}$ & 2.42 \\
\hline Insulin baseline $(\mu \mathrm{U} / \mathrm{ml})$ & $8 \cdot 38^{\mathrm{b}}$ & $6 \cdot 72$ \\
\hline Insulin $120 \mathrm{~min}(\mu \mathrm{U} / \mathrm{ml})$ & $45 \cdot 44^{b}$ & 44.91 \\
\hline Uric acid baseline $(\mu \mathrm{mol} / \mathrm{l})$ & $281.93^{\mathrm{C}}$ & $92 \cdot 19$ \\
\hline Uric acid $120 \mathrm{~min}(\mu \mathrm{mol} / \mathrm{l})$ & $267 \cdot 48^{\mathrm{C}}$ & $90 \cdot 40$ \\
\hline Total plasma proteins baseline $(\mathrm{g} / \mathrm{l})$ & 68.5 & $8 \cdot 80$ \\
\hline Total plasma proteins $120 \mathrm{~min}(\mathrm{~g} / \mathrm{l})$ & 68 & $8 \cdot 70$ \\
\hline HOMA-IR & $2 \cdot 18$ & 2.03 \\
\hline HOMA-IS & 91.40 & 93.60 \\
\hline
\end{tabular}

${ }^{*}$ For details of subjects and procedures, see Materials and methods.

${ }^{\mathrm{a}, \mathrm{b}, \mathrm{c}}$ Mean values were significantly different between before and after oral glucose tolerance test $(P<0.0001)$.

HOMA-IR, homeostasis model assessment insulin resistance; HOMAIS, homeostasis model assessment insulin secretion. 
(Mean values and standard deviations)

\begin{tabular}{|c|c|c|c|c|c|c|c|c|c|c|c|c|}
\hline & \multicolumn{4}{|c|}{ All } & \multicolumn{4}{|c|}{ Men $(n 227)$} & \multicolumn{4}{|c|}{ Women ( $n$ 429) } \\
\hline & \multicolumn{2}{|c|}{$<$ SP75 (n 492) } & \multicolumn{2}{|c|}{$>\delta \mathrm{P} 75(n 164)$} & \multicolumn{2}{|c|}{$<\delta \mathrm{P} 75(n$ 156) } & \multicolumn{2}{|c|}{$>\delta \mathrm{P} 75(n 71)$} & \multicolumn{2}{|c|}{$<\delta \mathrm{P} 75(n 336)$} & \multicolumn{2}{|c|}{$>$ SP75 (n 93) } \\
\hline & Mean & SD & Mean & SD & Mean & SD & Mean & SD & Mean & SD & Mean & SD \\
\hline Age (years) & $45 \cdot 82$ & $13 \cdot 6$ & $46 \cdot 9$ & $12 \cdot 6$ & 46.68 & 13.96 & 48.90 & $12 \cdot 14$ & $45 \cdot 54$ & 13.57 & $45 \cdot 58$ & 12.93 \\
\hline Sex & \multirow{2}{*}{\multicolumn{2}{|c|}{$\begin{array}{l}156 \\
336\end{array}$}} & \multirow{2}{*}{\multicolumn{2}{|c|}{71}} & \multirow{2}{*}{\multicolumn{2}{|c|}{-}} & \multirow{2}{*}{\multicolumn{2}{|c|}{-}} & \multirow{2}{*}{\multicolumn{2}{|c|}{-}} & \multirow{2}{*}{\multicolumn{2}{|c|}{-}} \\
\hline Women & & & & & & & & & & & & \\
\hline $\mathrm{TAG}(\mathrm{mmol} / \mathrm{l})$ & $1.17^{\mathrm{a}}$ & 0.73 & $1.53^{\mathrm{a}}$ & $1 \cdot 14$ & $1.44^{\mathrm{e}}$ & 0.84 & $1.87^{\mathrm{e}}$ & 1.48 & $1.04^{f}$ & 0.64 & $1.27^{f}$ & 0.71 \\
\hline HDL-cholesterol $(\mathrm{mmol} / \mathrm{l})$ & 1.76 & 0.42 & 1.73 & 0.43 & 1.65 & 0.35 & 1.70 & 0.34 & 1.80 & 0.44 & 1.76 & 0.49 \\
\hline LDL-cholesterol (mmol/l) & 4.17 & $1 \cdot 14$ & $4 \cdot 16$ & $1 \cdot 14$ & 4.24 & 1.29 & 4.19 & 1.39 & 4.15 & 1.07 & 4.15 & 0.99 \\
\hline BMI $(\mathrm{kg} / \mathrm{m} 2)$ & $28 \cdot 3$ & $5 \cdot 20$ & $28 \cdot 24$ & 5.068 & 28.41 & 4.12 & $28 \cdot 3$ & 4.021 & $28 \cdot 26$ & 5.579 & $28 \cdot 19$ & 5.68 \\
\hline Waist:hip ratio & 0.88 & 0.107 & 0.89 & $0 \cdot 10$ & 0.97 & 0.073 & 0.97 & 0.06 & 0.84 & 0.09 & 0.84 & 0.08 \\
\hline Insulin baseline $(\mu \mathrm{U} / \mathrm{ml})$ & $8 \cdot 10^{\mathrm{b}}$ & $5 \cdot 6$ & $9.55^{\mathrm{b}}$ & 9.8 & 8.8 & 5.90 & $9 \cdot 2$ & 6.78 & $7.7^{9}$ & $5 \cdot 4$ & $9 \cdot 8^{9}$ & 11.7 \\
\hline Systolic BP (mg Hg) & 131.47 & 64.9 & 134.52 & $74 \cdot 10$ & 137.58 & 18.80 & $138 \cdot 36$ & $20 \cdot 30$ & $128 \cdot 14$ & 56.60 & 134.71 & 94.70 \\
\hline Diastolic BP (mg Hg) & 81.90 & 65.80 & 84.7 & $76 \cdot 10$ & $83 \cdot 86$ & $11 \cdot 28$ & $84 \cdot 3$ & 11.60 & $79 \cdot 32$ & $56 \cdot 2$ & $86 \cdot 7$ & 98.00 \\
\hline HOMA-IS & $1.2^{\mathrm{c}}$ & $3 \cdot 10$ & $1.99^{c}$ & 5.0 & 1.39 & 3.10 & 1.66 & 3.60 & $1 \cdot 12^{\mathrm{h}}$ & 3.20 & $2 \cdot 2^{h}$ & 5.90 \\
\hline HOMA-IR & $2 \cdot 12^{\mathrm{d}}$ & 1.60 & $2.53^{\mathrm{d}}$ & 2.99 & 2.45 & $1 \cdot 80$ & $2 \cdot 5$ & $2 \cdot 0$ & $1.9^{i}$ & 1.50 & $2.54^{i}$ & 3.50 \\
\hline
\end{tabular}

${ }^{*}$ For details of subjects and procedures, see Materials and methods.

Pe

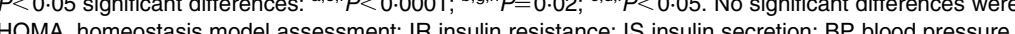

Table 3. Correlation analysis of the biological variables studied (Pearson r) $\dagger$

\begin{tabular}{|c|c|c|c|c|c|c|c|c|c|c|c|c|c|}
\hline & HOMA-IS & HOMA-IR & insulin 120 & insulin bas & Gly bas & Gly $120^{\prime}$ & Uric acid & TG & Chol & HDL-chol & W-H & BMI & Age \\
\hline HOMA IR & $0.710^{*}$ & & & & & & & & & & & & \\
\hline Insulin 120 & $0.463^{*}$ & $0.565^{*}$ & & & & & & & & & & & \\
\hline Insulin bas & $0.935^{\star}$ & $0.902^{*}$ & $0.525^{\star}$ & & & & & & & & & & \\
\hline Gly bas & 0.015 & $0.588^{\star}$ & $0.300^{*}$ & $0.287^{*}$ & & & & & & & & & \\
\hline Gly $120^{\prime}$ & $0.224^{\star}$ & $0.334^{\star}$ & $0.584^{\star}$ & $0.292^{\star}$ & $0.342^{*}$ & & & & & & & & \\
\hline Úric acid & $0.208^{\star}$ & $0.233^{\star}$ & $0.225^{\star}$ & $0.252^{*}$ & $0.194^{\star}$ & $0.193^{\star}$ & & & & & & & \\
\hline TG & $0.184^{*}$ & $0.304^{*}$ & $0.316^{*}$ & $0.272^{*}$ & $0.307^{\star}$ & $0.267^{\star}$ & $0.420^{\star}$ & & & & & & \\
\hline Chol & -0.010 & 0.051 & $0.139^{\star}$ & 0.033 & $0.120^{*}$ & $0.111^{\star}$ & $0.161^{*}$ & $0.314^{\star}$ & & & & & \\
\hline HDL col. & $-0.109^{\star}$ & $-0.067^{\star}$ & 0.0001 & $-0.097^{\star}$ & -0.006 & 0.009 & $-0.089^{*}$ & -0.050 & $0.359^{*}$ & & & & \\
\hline $\mathrm{W}-\mathrm{H}$ & $0.317^{\star}$ & $0.409^{*}$ & $0.337^{*}$ & $0.399^{*}$ & $0.340^{*}$ & $0.285^{*}$ & $0.377^{\star}$ & $0.297^{\star}$ & $0.253^{*}$ & -0.046 & & & \\
\hline Age & $0.159^{*}$ & $0.290^{*}$ & $0.292^{\star}$ & $0.249^{*}$ & $0.331^{*}$ & $0.288^{*}$ & $0.180^{*}$ & $0 \cdot 161^{*}$ & $0.285^{\star}$ & 0.030 & $0.604^{*}$ & $0.378^{\star}$ & \\
\hline$\delta \cup A$ & 0.032 & 0.057 & -0.044 & 0.049 & 0.047 & $0.092^{*}$ & $0.444^{*}$ & $0.232^{*}$ & $0 \cdot 108^{*}$ & -0.007 & 0.045 & 0.024 & 0.055 \\
\hline
\end{tabular}

Statistical significance: * $P<0.05$. No significant differences were detected according to sex.

For details of subjects and procedures, see Materials and methods.

UA, difference uric acid; Chol, cholesterol; insulin bas, insulin baseline; HOMA, homeostasis model assessment; IR, insulin resistance; IS, insulin secretion; W-H, waist:hip ratio; Gly bas, glycaemia basal; Gly 120, glycaemia 120. 
Multiple regression analysis with the difference in the uric acid levels between baseline and $120 \mathrm{~min}$ after the OGTT as the dependent variable showed that the TAG levels, insulin $120 \mathrm{~min}$, glycaemia $120 \mathrm{~min}$ and waist:hip ratio significantly predicted the variance in the uric acid difference $\left(r^{2} 0 \cdot 077\right)$ (Table 4). The following variables failed to enter the model: baseline insulin; baseline and 120-min glycaemia; HDL-cholesterol; cholesterol; HOMA-IS; HOMA-IR. Separate analysis showed no difference according to sex.

\section{Discussion}

The main finding in the present study was that uric acid levels drop after a glucose challenge and this change is dependent on TAG levels and insulin resistance. The reasons for this reduction may include reduced synthesis of uric acid after a glucose challenge; increasing renal excretion of urates, although this is physiologically unlikely as uric acid excretion in $2 \mathrm{~h}$ is not enough to produce a drop in plasma levels of uric acid; a reduction due to the effect of dilution in serum after the glucose challenge, which again is unlikely as no change was seen in levels of total plasma proteins. A final possibility is that this reduction is due to the consumption of uric acid as it carries out its antioxidant function. In line with our hypothesis, the latter option is most likely. The reduction in uric acid levels after an OGTT with $75 \mathrm{~g}$ glucose may have an important biological meaning, since it highlights the role of uric acid as an antioxidant in plasma in a situation that increases oxidative stress, as is a glucose challenge.

An increase in oxidative stress occurs after an OGTT in persons with and without diabetes ${ }^{15,16}$. Several studies in patients with type 2 diabetes have reported the generation of oxidative stress during the postprandial period. These observations suggest that control of glucose excursions, and accompanying oxidative stress, during the postprandial period may be important in the prevention of potential long-term diabetes complications ${ }^{16,25,26}$. This increase potentially influences the

Table 4. Multiple regression analysis*

\begin{tabular}{llrccc}
\hline Model & & $\beta$ & SE & $P$ & $R^{2}$ \\
\hline 1 & TAG & 0.210 & 0.001 & 0.000 & 0.044 \\
& & & & & \\
2 & TAG & 0.246 & 0.001 & 0.000 & 0.057 \\
& insulin 120 & -0.122 & 0.001 & 0.009 & \\
3 & TAG & 0.229 & 0.001 & 0.000 & 0.070 \\
& insulin 120 & -0.206 & 0.002 & 0.000 & \\
& Glycaemia 120 & 0.144 & 0.002 & 0.011 & \\
& & & & & \\
& TAG & 0.202 & 0.001 & 0.000 & 0.077 \\
& insulin 120 & -0.220 & 0.002 & 0.000 & \\
& Glycaemia 120 & 0.133 & 0.002 & 0.019 & \\
& WHR & 0.095 & 0.622 & 0.049 & \\
& & & & &
\end{tabular}

${ }^{*}$ For details of subjects and procedures, see Materials and methods.

Dependent variable: difference uric acid ( $\delta \mathrm{UA})$; independent variables: cholesterol, uric acid, age, $\mathrm{BMI}$, LDL-cholesterol, homeostasis model assessment insulin resistance (HOMA-IR), homeostasis model assessment insulin secretion (HOMA-IS), insulin, insulin $120 \mathrm{~min}$, glucose, glucose $120 \mathrm{~min}$

Statistical significance: $P<0.05$.

Variables not entering the model: baseline insulin, baseline glycaemia, HDL-cholesterol, cholesterol, BMI, age, HOMA-IS and HOMA-IR. No significant differences were detected according to sex.

WHR, waist:hip ratio. urate levels by two different mechanisms: 1) the reduction of the plasma level of uric acid after a glucose challenge is due to the consumption of uric acid after its sudden participation in antioxidant reactions. Allantoin is formed from the non-enzymatic oxidation of urate and it is a marker of the antioxidant effect of uric acid ${ }^{27}$. Thus, the reduction in plasma levels of uric acid may be at the expense of increased levels of allantoin, after carrying out its antioxidant function; 2) experimental and clinical studies have shown that uric acid levels rise in response to chronic oxidative stress ${ }^{28,29}$.

The drop in plasma levels of uric acid may be due to less synthesis, as a result of the inhibition of xanthine oxidase by the high degree of postprandial oxidative stress as a consequence of high levels of free radicals ${ }^{30,31}$. We therefore propose a hypothesis according to which situations of acute stress produce a small decrease in the levels of uric acid, due to the consumption of uric acid as it carries out its antioxidant function and conversely that chronic stress would induce a permanent increase in uric acid levels.

The association between hyperuricaemia and hypertriacylglycerolaemia has been known for some time. Two different phenotypes exist, pure hyperuricaemic persons and persons with both hyperuricaemia and hypertriacylglycerolaemia ${ }^{32}$. Fox et al. found that environmental factors such as diet were responsible for this association of hypertriacylglycerolaemia and hyperuricaemia ${ }^{33}$. Furthermore, our group has detected this association of hypertriacylglycerolaemia and hyperuricaemia even in the absence of these environmental factors ${ }^{34}$ and evidence exists for genetic associations between these two metabolic disorders and several genes ${ }^{4-6}$. The results of the present study show that the decrease in uric acid levels after a glucose challenge is closely associated with baseline TAG levels and with variables associated with insulin resistance in the general population and support the association between hypertriacylglycerolaemia and hyperuricaemia found previously ${ }^{7}$. A possible explanation for this is that persons with hypertriacylglycerolaemia and insulin resistance have greater oxidative stress, with the consequent greater consumption of uric acid. Hypertriacylglycerolaemia produces a rise in oxidative stress via an increase in free radicals, particularly in superoxide anions proceeding from the increased proton gradient in the mitochondria as a result of excess acetyl CoA after $\beta$-oxidation of NEFA derived from the TAG; an increase that is reverted with antioxidants ${ }^{35,36}$.

In conclusion, this study showed that in a situation that increases oxidative stress, as is an OGTT, there is an acute drop in levels of uric acid and that those persons who experience the greatest reduction have greater insulin resistance and higher TAG levels. Whether this reduction in uric acid concentration is associated with the antioxidant effect of uric acid remains to be shown.

\section{Acknowledgements}

The authors wish to thank all the subjects for their collaboration and IMABIS. We also gratefully acknowledge the help of Ian Johnstone for his expertise in preparing this manuscript. This study was undertaken with finance from the Fondo de Investigación Sanitaria 'Centros de Investigación En Red' (CIBER, CB06/03/0018) of the 'Instituto de Salud Carlos III', SAF 2006/12 894 of the MCYT and FIS 05/1307 of the 
'Instituto de Salud Carlos III', Madrid, Spain. The investigation group belongs to the 'Red de Diabetes y Metabolismo' (RD06/0015/0008) of the Instituto de Salud Carlos III.

\section{References}

1. Zavaroni I, Mazza S, Fantuzzi M, Dall'Aglio E, Bonora E, Delsignore R, Passeri M \& Reaven GM (1993) Changes in insulin and lipid metabolism in males with asymptomatic hyperuricaemia. J Intern Med 234, 25-30.

2. Rathman W, Funkhouser E, Dyer AR \& Roseman JM (1998) Relations of hyperuricemia with the various components of the insulin resistance syndrome in young black and white adults: The Cardia Study. Ann Epidemiol 8, 250-261.

3. Culleton BF, Larson MG, Kannel WB \& Levy D (1999) Serum uric acid and risk for cardiovascular disease and death: the Framingham Heart Study. Ann Intern Med 131, 7-13.

4. Cardona F, Tinahones FJ, Collantes E, Escudero A, GarciaFuentes E \& Soriguer FJ (2005) Contribution of polymorphisms in the apolipoprotein AI- CIII-AIV cluster to hyperlipidaemia in patients with gout. Ann Rheum Dis 64, 85-88.

5. Cardona F, Tinahones FJ, Collantes E, Escudero A, GarciaFuentes E \& Soriguer FJ (2003) The elevated prevalence of apolipoprotein E2 in patients with gout is associated with reduced renal excretion of urates. Rheumatology (Oxford) 42, 468-472.

6. Cardona F, Tinahones FJ, Collantes E, Garcia-Fuentes E, Escudero A \& Soriguer F (2005) Response to a urate-lowering diet according to polymorphisms in the apolipoprotein AI-CIIIAIV cluster. J Rheumatol 32, 903-905.

7. Tinahones JF, Pérez-Lindon G, C-Soriguer FJ, Pareja A, Sánchez-Guijo P \& Collantes E (1997) Dietary alterations in plasma very low density lipoprotein levels modify renal excretion of urates in hyperuricemic-hypertriglyceridemic patients. J Clin Endocrinol Metab 82, 1188-1191.

8. Facchini F, Chen YD, Hollenbeck CB \& Reaven GM (1991) Relationship between resistance to insulin-mediated glucose uptake, urinary uric acid clearance, and plasma uric acid concentration. JAMA 266, 3008-3011.

9. Quinones Galvan A, Natali A, Baldi S, Frascerra S, Sanna G, Ciociaro D \& Ferrannini E (1995) Effect of insulin on uric acid excretion in humans. Am J Physiol 268, E1-E5.

10. Cardona F \& Tinahones FJ (2006) The missing link in the metabolic syndrome: Postprandial hyperlipidemia and oxidative stress. Endocrinología 53, 345-352.

11. Berry CE \& Hare JM (2004) Xanthine oxidoreductase and cardiovascular disease: molecular mechanisms and pathophysiological implications. J Physiol 16, 589-606.

12. Farquharson CA, Butler R, Hill A, Belch JJ \& Struthers AD (2002) Allopurinol improves endothelial dysfunction in chronic heart failure. Circulation 106, 221-226.

13. Waring WS, Webb DJ \& Maxwell SR (2001) Systemic uric acid administration increases serum antioxidant capacity in healthy volunteers. J Cardiovasc Pharmacol 38, 365-371.

14. Waring WS, Convery A, Mishra V, Shenkin A, Webb DJ \& Maxwell SR (2003) Uric acid reduces exercise-induced oxidative stress in healthy adults. Clin Sci (Lond) 105, 425-430.

15. Ceriello A (1997) Acute hyperglycaemia and oxidative stress generation. Diabet Med 14, S45-S49.

16. Ceriello A, Bortolotti N, Motz E, Crescentini A, Lizzio S, Russo A, Tonutti L \& Taboga C (1998) Meal-generated oxidative stress in type 2 diabetic patients. Diabetes Care 21, 1529-1533.

17. Brownlee M (2001) Biochemistry and molecular cell biology of diabetic complications. Nature 414, 813-820.

18. Ceriello A, Bortolotti N, Crescentini A, Motz E, Lizzio S, Russo A, Ezsol Z, Tonutti L \& Taboga C (1998) Antioxidant defenses are reduced during oral glucose tolerance test in normal and non-insulin dependent diabetic subjects. Eur J Clin Invest 28, 329-333.

19. Tessier D, Khalil A \& Fulop T (1999) Effects of an oral glucose challenge on free radicals/antioxidants balance in an older population with type II diabetes. J Gerontol 54, 541-545.

20. Konukoglu D, Hatemi H, Ozer EM, Gonen S \& Akcay T (1997) The erythrocyte glutathione levels during oral glucose tolerance test. J Endocrinol Invest 20, 471-475.

21. Zou MH, Shi C \& Cohen RA (2002) Oxidation of the zinc-thiolate complex and uncoupling of endothelial nitric oxide synthase by peroxynitrite. J Clin Invest 109, 817-826.

22. Rojo-Martinez G, Esteva I, Ruiz de Adana MS, Garcia-Almeida JM, Tinahones F, Cardona F, Morcillo S, Garcia-Escobar E, Garcia-Fuentes E \& Soriguer F (2006) Dietary fatty acids and insulin secretion: a population-based study. Eur J Clin Nutr 60, $1195-1200$.

23. Andalusian Statistics Institute (1996) Municipal information system of Andalusia. Seville: Andalusian Parliament.

24. Matthews DR, Hosker JP, Rudenski AS, Naylor BA, Treacher DF \& Turner RC (1985) Homeostasis model assessment: insulin resistance and beta-cell function from fasting plasma glucose and insulin concentrations in man. Diabetologia 28, 412-419.

25. Ceriello A, Bortolotti N, Motz E, Pieri C, Marra M, Tonutti L, Lizzio S, Feletto F, Catone B \& Taboga C (1999) Meal-induced oxidative stress and low-density lipoprotein oxidation in diabetes: the possible role of hyperglycemia. Metabolism 48, 1503-1508.

26. Ceriello A (2003) The possible role of postprandial hyperglycaemia in the pathogenesis of diabetic complications. Diabetologia 46, M9-M16.

27. Benzie IF, Chung W \& Tomlinson B (1999) Simultaneous measurement of allantoin and urate in plasma: analytical evaluation and potential clinical application in oxidant:antioxidant balance studies. Clin Chem 45, 901-904.

28. Ozguner F, Armagan A, Koyu A, Caliskan S \& Koylu H (2005) A novel antioxidant agent caffeic acid phenethyl ester prevents shock wave-induced renal tubular oxidative stress. Urol Res 33, 239-243.

29. Elmas O, Aslan M, Caglar S, Derin N, Agar A, Aliciguzel Y \& Yargicoglu P (2005) The prooxidant effect of sodium metabisulfite in rat liver and kidney. Regul Toxicol Pharmacol 42, 77-82.

30. McNally JS, Saxena A, Cai H, Dikalov S \& Harrison DG (2005) Regulation of xanthine oxidoreductase protein expression by hydrogen peroxide and calcium. Arterioscler Thromb Vasc Biol 25, 1623-1628.

31. Mueller CF, Laude K, McNally JS \& Harrison DG (2005) ATVB in focus: redox mechanisms in blood vessels. Arterioscler Thromb Vasc Biol 25, 274-278.

32. Collantes E, Tinahones FJ, Cisnal A, Anon J \& Sanchez-Guijo P (1994) Variability of lipid phenotypes in hyperuricaemic-hyperlipidemic patients. Clin Rheumatol 13, 244-247.

33. Fox IH, John D, DeBruyne S, Dwosh I \& Marliss EB (1985) Hyperuricemia and hypertriglyceridemia: Metabolic basis for the association. Metabolism 34, 741-746.

34. Collantes Estevez E, Pineda Priego M, Anon Barbudo J \& Sanchez Guijo P (1990) Hyperuricemia-Hyperlipemia association in the absence of obesity and alcohol abuse. Clin Rheumatol 9, 28-31.

35. Ceriello A, Assaloni R, Da Ros R, Maier A, Piconi L, Quagliaro L, Esposito K \& Giugliano D (2005) Effect of atorvastatin and irbesartan, alone and in combination, on postprandial endothelial dysfunction, oxidative stress, and inflammation in type 2 diabetic patients. Circulation 111, 2518-2524.

36. Ceriello A \& Motz E (2004) Is oxidative stress the pathogenic mechanism underlying insulin resistance, diabetes, and cardiovascular disease? The common soil hypothesis revisited. Arterioscler Thromb Vasc Biol 24, 816-823. 